\title{
Loss of Traces of Antimony and Arsenic due to Volatilization during Dissolution of Aluminum Metal Samples
}

\author{
Atsushi Mizuike and Tomio Kono \\ Faculty of Engineering, Nagoya University, Chikusa-ku, Nagoya, Japan \\ Received September 1, 1970
}

\section{Introduction}

In trace element analysis of metals, especially for impurities at the low ppm or ppb level, the samples are often dissolved in various acids and other solvents prior to separation or determination steps. Loss by partial volatilization of desired trace elements may occur during the dissolution and result in significant negative errors in final analytical values. However, the literature which deals with this subject is scanty. In the present work, loss of fractional ppm of antimony and arsenic in high-purity aluminum metal (99.99\%) during the dissolution step is investigated because of possible volatilization of both elements as hydrides or halides. Antimony-124 and arsenic-76 produced in the metal samples by thermal neutron irradiation in a nuclear reactor act as tracers in this experiment. The solvents used include $5 \mathrm{M}$ sodium hydroxide, concentrated and $9 M$ hydrochloric acid containing traces of nickel ions* and aqua regia.

\section{Experimental}

\section{$2 \cdot 1$ Nuclear reactor}

Japan Atomic Energy Research Institute research reactor JRR-2 (10 MW).

2 . 2 Radiation detectors and pulse height analyzers

A Harshaw and a Fujitsu $\mathrm{NaI}(\mathrm{Tl})$ scintillation detector.

A TMC 400-channel, a TMC 256-channel and a Fujitsu 100-channel pulse height analyzer.

2 - 3 Decomposition and absorption vessels

A decomposition vessel and absorption tubes are shown in Fig. 1. Also, 100-m $l$ Erlenmeyer flasks and beakers are used instead of the

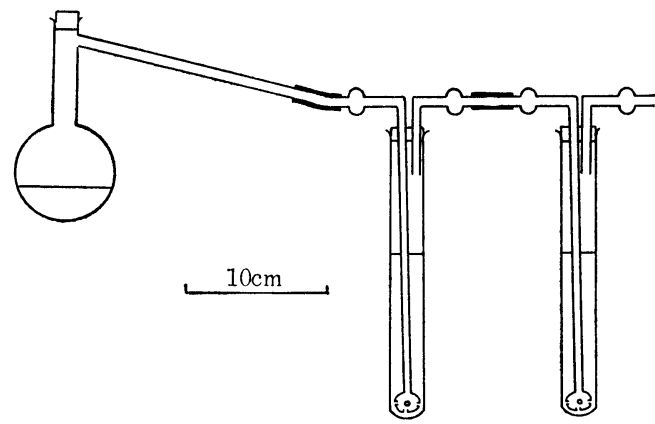

Fig. 1 Decomposition vessel and absorption tubes. absorption tubes.

\section{4 Material and reagents}

Aluminum metal: $99.99 \%$ purity ingot.

Antimony calibration standards, 0-1 $\mu \mathrm{g} \mathrm{Sb}$ : Dissolve $1.00 \mathrm{~g}$ of antimony metal (99.999\%) in $20 \mathrm{ml}$ of aqua regia, add $30 \mathrm{ml}$ of $\mathrm{HCl}$, and dilute to $100 \mathrm{~m} l$ with water. Dilute this stock solution (10 $\mathrm{mg} \mathrm{Sb} / \mathrm{ml}$ ) to appropriate concentrations with a 1:20 mixture of aqua regia and water. Place a $0.1-\mathrm{m} l$ aliquot on a $4 \times 4 \mathrm{~cm}^{2}$ aluminum foil (ca. $0.09 \mathrm{~g}$ ), neutralize with $1 \mathrm{M} \mathrm{NH}{ }_{4} \mathrm{OH}$, and evaporate to dryness under an infrared lamp.

Arsenic calibration standards, 0-1 $\mu \mathrm{g}$ As: Dissolve $1.32 \mathrm{~g}$ of $\mathrm{As}_{2} \mathrm{O}_{3}$ in $5 \mathrm{ml}$ of $\mathrm{HCl}, 10 \mathrm{ml}$ of $\mathrm{HNO}_{3}$, and $10 \mathrm{ml}$ of water. Evaporate the solution to $5 \mathrm{~m} l$, and dilute to $100 \mathrm{~m} l$ with water. Dilute this stock solution (10 mg As/ $\mathrm{ml}$ ) to appropriate concentrations with a $1: 20$ mixture of aqua regia and water. Place a 0.1 $-\mathrm{m} l$ aliquot on a $3-\mathrm{cm}$ filter paper (No. 7), and evaporate to dryness under an infrared lamp.

Antimony (III) carrier solution, $10 \mathrm{mg} \mathrm{Sb} / \mathrm{ml}$ : Dissolve $4.68 \mathrm{~g}$ of $\mathrm{SbCl}_{3}$ in $45 \mathrm{ml}$ of $\mathrm{HCl}$, and dilute to $250 \mathrm{~m} l$ with water.

Antimony $(\nabla)$ carrier solution, $10 \mathrm{mg} \mathrm{Sb} /$ $\mathrm{m} l$ : Dissolve $1.00 \mathrm{~g}$ of antimony metal in $20 \mathrm{~m} l$

* Nickel ions accelerate the dissolution. 
of aqua regia, add $30 \mathrm{ml}$ of $\mathrm{HCl}$, and dilute

to $100 \mathrm{~m} l$ with water.

Arsenic (III) carrier solution, $10 \mathrm{mg} \mathrm{As} / \mathrm{m} l$ : Dissolve $3.30 \mathrm{~g}$ of $\mathrm{As}_{2} \mathrm{O}_{3}$ in $16 \mathrm{ml}$ of $2.5 \mathrm{M}$ $\mathrm{NaOH}$, add $20 \mathrm{~m} l$ of $6 \mathrm{M} \mathrm{HCl}$, and dilute to $250 \mathrm{~m} l$ with water.

Arsenic $(V)$ carrier solution, $10 \mathrm{mg} \mathrm{As} / \mathrm{ml}$ : Dissolve $10.4 \mathrm{~g}$ of $\mathrm{Na}_{2} \mathrm{HAsO}_{4} \cdot 7 \mathrm{H}_{2} \mathrm{O}$ in $10 \mathrm{ml}$ of $1 \mathrm{M} \mathrm{NaOH}$, and dilute to $250 \mathrm{~m} l$ with water.

Cadmium carrier solution, $10 \mathrm{mg} \mathrm{Cd} / \mathrm{m} l$ : Dissolve $2.74 \mathrm{~g}$ of $\mathrm{Cd}\left(\mathrm{NO}_{3}\right)_{2} \cdot 4 \mathrm{H}_{2} \mathrm{O}$ in water, and dilute to $100 \mathrm{~m} l$ with water.

Copper( II) carrier solution, $10 \mathrm{mg} \mathrm{Cu} / \mathrm{m} l$ : Dissolve $3.93 \mathrm{~g}$ of $\mathrm{CuSO}_{4} \cdot 5 \mathrm{H}_{2} \mathrm{O}$ in water, and dilute to $100 \mathrm{~m} l$ with water.

All the reagents used were of reagent grade. Water purified by distillation and ion exchange was used throughout the work.

\section{$2 \cdot 5$ Procedures}

For antimony Wash $1-\mathrm{g}$ cube aluminum samples with petroleum benzine, ethanol, hydrochloric acid, and water, and dry at $40^{\circ} \mathrm{C}$ in an oven. Wrap each sample in aluminum foil, pack into an aluminum capsule $(24 \mathrm{~mm}$ dia. $\times 62 \mathrm{~mm}$ ) together with antimony calibration standards, and irradiate in a reactor at a thermal neutron flux of $4 \times 10^{13} \mathrm{n} / \mathrm{cm}^{2} \cdot \mathrm{sec}$ for 200 300 hrs.

After cooling, cut the irradiated samples into small chips (ca. $1 \mathrm{~mm}$ in size) using a chisel and nippers, wash with petroleum benzine, ethanol, hydrochloric acid, and water, and dry at $40^{\circ} \mathrm{C}$ in an oven.

Transfer ca. $1 \mathrm{~g}$ of the chips to a decomposition vessel, connect absorption vessels containing absorbents, add $20 \mathrm{ml}$ of $5 \mathrm{M}$ sodium hydroxide, $30 \mathrm{~m} l$ of hydrochloric acid containing $0.1 \mathrm{mg}$ of nickel ions, or $30 \mathrm{ml}$ of aqua regia to the decomposition vessel, and heat gently to dissolve. When the sample has completely dissolved, rinse the sidearm of the decomposition vessel with a small amount of water, transfer each solution in the decomposition and the absorption vessels to a $100-\mathrm{m} l$ beaker, and add $5 \mathrm{~m} l$ of antimony $(\nabla)$ carrier solution** and $1 \mathrm{~m} l$ of cadmium carrier solution. Evaporate the solution to dryness***, and add hydrochloric acid and water to give $90 \mathrm{~m} l$ of $4 M$ hydrochloric acid solution.

Transfer the solution to a 200-m $l$ Erlenmeyer flask, and pass hydrogen sulfide for $5 \mathrm{~min}$. Filter off the precipitate on a filter paper $(5 \mathrm{C})$, and wash with $20 \mathrm{~m} l$ of $4 M$ hydrochloric acid. Dissolve the precipitate in $25 \mathrm{ml}$ of hydrochloric acid, catching the solution in a $100-\mathrm{m} l$ beaker. Add $15 \mathrm{~m} l$ of water to the solution and boil for $2 \mathrm{~min}$. Transfer the solution to a $300-\mathrm{m} l$ Erlenmeyer flask, add $85 \mathrm{~m} l$ of water, and pass a rapid stream of hydrogen sulfide at $90^{\circ} \mathrm{C}$ until the orange precipitate turns black.

Filter off the precipitate on a glass filter crucible (1G4), and wash with $20 \sim 30 \mathrm{~m} l$ of water followed by $10 \mathrm{~m} l$ of ethanol. Pour five $5 \mathrm{~m} l$ portions of carbon disulfide into the crucible, stir for a few min to dissolve sulfur, and then remove the solvent by suction. Finally, wash the precipitate with $30 \mathrm{~m} l$ of ethanol, and dry at $105^{\circ} \mathrm{C}$ for $90 \mathrm{~min}$. Cool the precipitate, transfer to a polyethylene test tube, weigh as $\mathrm{Sb}_{2} \mathrm{~S}_{3}$, and measure the gamma spectrum. Correct the radioactivity (photopeak area) using the chemical yield, and determine the amount of antimony by reference to a calibration curve. Confirm the radiochemical purity by measuring the decay.

For the construction of the calibration curve, dissolve each irradiated antimony calibration standard in $30 \mathrm{~m} l$ of hydrochloric acid, add $5 \mathrm{~m} l$ of antimony (II) carrier solution and $1 \mathrm{~m} l$ of cadmium carrier solution, dilute with water to give $90 \mathrm{~m} l$ of $4 M$ hydrochloric acid solution, pass hydrogen sulfide, and proceed as described above.

For arsenic Wash aluminum chips (ca. $1 \times 2 \times 8 \mathrm{~mm}^{3}$, prepared by a lathe) with petroleum benzine, ethanol, hydrochloric acid, and water, and dry at $40^{\circ} \mathrm{C}$ in an oven. Wrap the chips in polyethylene sheet, pack into a polyethylene capsule $(24 \mathrm{~mm}$ dia. $\times 62 \mathrm{~mm}$ ) together with arsenic calibration standards, and irradiate in a reactor at a thermal neutron flux of $8 \times 10^{13}$ $n / \mathrm{cm}^{2} \cdot \mathrm{sec}$ for $20 \mathrm{~min}$.

** Omit this solution when antimony carrier is present. Use antimony (III) carrier when nitric acid is absent from the solution.

*** Omit this operation when nitric acid is absent from the solution. 
After cooling, transfer $1 \mathrm{~g}$ of the sample to a decomposition vessel, connect absorption vessels containing absorbents, add $20 \mathrm{ml}$ of $5 \mathrm{M}$ sodium hydroxide, $30 \mathrm{~m} l$ of hydrochloric acid ( $12 M$ and $9 M$ ) containing $0.1 \mathrm{mg}$ of nickel ions, or $30 \mathrm{ml}$ of aqua regia, and heat gently to dissolve. When the sample has completely dissolved, rinse the sidearm of the decomposition vessel with a small amount of water, transfer each solution in the decomposition and the absorption vessels to a $200-$ or $400-\mathrm{m} l$ beaker, and add $5 \mathrm{~m} l$ of $\operatorname{arsenic}(\mathrm{V})$ carrier solution****. Evaporate the solution to dryness***, and add hydrochloric acid and water to give $40 \sim 120 \mathrm{~m} l$ of $9 \mathrm{M}$ hydrochloric acid. Filter off the precipitate, on a filter paper $(5 \mathrm{C})$, if any, catching the filtrate in another $400-\mathrm{m} l$ beaker. Add ca. $1 \mathrm{mg}$ of potassium iodide to the filtrate, and pass sulfur dioxide for $10 \mathrm{~min}$. Dilute the solution with water to $4 M$ in acidity, and pass nitrogen for $40 \mathrm{~min}$ to expel sulfur dioxide. Add $1 \mathrm{~m} l$ each of copper( II) and antimony (III) carrier solutions, and hydrochloric acid to give $6 M$ hydrochloric acid solution.

Pass hydrogen sulfide into the solution at $60^{\circ} \mathrm{C}$ for $5 \mathrm{~min}$. Allow to stand for $20 \sim 30$ min at $60^{\circ} \mathrm{C}$, filter off the precipitate on a filter paper (5C), and wash with $10 \mathrm{~m} l$ of $6 \mathrm{M}$ hydrochloric acid followed by $30 \mathrm{~m} l$ of water. Dissolve the precipitate in $40 \mathrm{~m} l$ of $1 \mathrm{M}$ sodium hydroxide, and add $10 \mathrm{~m} l$ of hydrochloric acid at $60^{\circ} \mathrm{C}$ to reprecipitate the arsenic (III) sulfide.

Table 1 Experimental results for antimony

\begin{tabular}{|c|c|c|c|c|c|c|c|c|}
\hline \multirow{2}{*}{$\begin{array}{l}\text { Exp. } \\
\text { No. }\end{array}$} & \multirow{2}{*}{$\begin{array}{l}\text { Sample } \\
\text { taken (g) }\end{array}$} & \multirow{2}{*}{ Solvent } & \multirow{2}{*}{ Vessel } & \multirow{2}{*}{$\begin{array}{l}\text { Chemical } \\
\text { yield }(\%)\end{array}$} & \multirow{2}{*}{$\begin{array}{l}\text { Radioactivity*7 } \\
(\mathrm{cpm})\end{array}$} & \multicolumn{3}{|c|}{$\mathrm{Sb}$} \\
\hline & & & & & & $\mu \mathrm{g}$ & ppm is & $\mathrm{Al}$ \\
\hline \multirow{9}{*}{$1^{* 1}$} & \multirow{3}{*}{ (1. 10} & \multirow{3}{*}{$\begin{array}{l}5 \underset{20 \mathrm{maOH}}{\mathrm{M} l} \\
\end{array}$} & Decomposition & 84 & 6992 & 0.25 & 0.23 & \multirow{3}{*}{0.26} \\
\hline & & & 1 st absorption $* 3$ & 82 & 343 & \multirow{2}{*}{0.03} & \multirow{2}{*}{0.03} & \\
\hline & & & 2 nd absorption $* 4$ & 78 & 349 & & & \\
\hline & \multirow{3}{*}{1.06} & \multirow{3}{*}{$\begin{array}{l}\mathrm{HCl}, 30 \mathrm{ml} \\
(+0.1 \mathrm{mg} \mathrm{Ni})\end{array}$} & Decomposition & 80 & 7830 & 0.28 & 0.26 & \multirow{4}{*}{0.26} \\
\hline & & & 1 st absorption*3 & 83 & 0 & 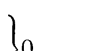 & & \\
\hline & & & 2 nd absorption ${ }^{* 4}$ & 77 & 0 & \}$^{0}$ & 0 & \\
\hline & \multirow{3}{*}{ 1. 11} & \multirow{3}{*}{$\begin{array}{l}\text { Aqua regia, } \\
30 \mathrm{ml}\end{array}$} & Decomposition & 53 & 8787 & 0.31 & 0.28 & \\
\hline & & & 1 st absorption $* 3$ & 56 & 0 & 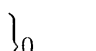 & & \multirow[t]{2}{*}{0.28} \\
\hline & & & 2 nd absorption ${ }^{* 4}$ & 46 & 0 & $\int^{0}$ & 0 & \\
\hline \multirow{9}{*}{$2^{* 2}$} & \multirow{3}{*}{1.05} & \multirow{3}{*}{$\begin{array}{l}5 \mathrm{M} \mathrm{NaOH}, \\
20 \mathrm{ml}\end{array}$} & Decomposition & 79 & 9922 & 0.23 & 0.22 & \multirow{3}{*}{0.23} \\
\hline & & & 1 st absorption $* 5$ & 80 & 323 & & 0 & \\
\hline & & & 2 nd absorption ${ }^{* 5}$ & 80 & 139 & & 0.01 & \\
\hline & \multirow{3}{*}{0.87} & \multirow{3}{*}{$\begin{array}{l}\mathrm{HCl}, 30 \mathrm{ml} \\
(+0.1 \mathrm{mg} \mathrm{Ni})\end{array}$} & Decomposition & 78 & 9297 & 0.22 & 0.25 & \multirow{3}{*}{0.25} \\
\hline & & & 1 st absorption $* 5$ & 81 & 48 & & 0 & \\
\hline & & & 2 nd absorption*s & 80 & 0 & & 0.001 & \\
\hline & \multirow{3}{*}{1.07} & \multirow{3}{*}{$\begin{array}{l}\text { Aqua regia, } \\
30 \mathrm{ml}\end{array}$} & Decomposition & 58 & 10759 & 0.25 & 0.23 & \multirow{3}{*}{\} 0.23} \\
\hline & & & 1 st absorption $* 6$ & 49 & 0 & 0 & 0 & \\
\hline & & & 2 nd absorption $* 6$ & \multicolumn{2}{|c|}{ (not determined) } & & & \\
\hline
\end{tabular}

*1 Irradiation time: $200 \mathrm{hrs}$. Cooling time: 71 days.

*2 Irradiation time: 288 hrs. Cooling time: 70 days.

*3 $100-\mathrm{m} l$ Erlenmeyer flask containing $30 \mathrm{~m} l$ of water.

*4 $100-\mathrm{m} l$ Erlenmeyer flask containing $30 \mathrm{~m} l$ of $\mathrm{HCl}$.

*5 Absorption tube containing $30 \mathrm{~m} l$ of $\mathrm{HCl}$ and $5 \mathrm{ml}$ of $\mathrm{Sb}(\mathbb{I I})$ carrier solution.

*6 Absorption tube containing $30 \mathrm{~m} l$ of $\mathrm{HCl}$ and $5 \mathrm{ml}$ of $\mathrm{Sb}(\mathrm{V})$ carrier solution.

*7 Measured 71 days after the end of irradiation, and corrected for chemical yield.

Allow to stand for $10 \sim 15 \mathrm{~min}$ at $60^{\circ} \mathrm{C}$, and filter off the precipitate on a glass filter crucible (1G4). Wash the precipitate with hydrochloric
**** Omit this solution when arsenic carrier is present. Use arsenic (III) carrier when nitric acid is absent from the solution. 
acid, water, ethanol, carbon disulfide, and ethanol, dry at $105^{\circ} \mathrm{C}$ for $1 \mathrm{hr}$, cool, weigh as $\mathrm{As}_{2} \mathrm{~S}_{3}$, measure the gamma spectrum, and determine the amount of arsenic, as described for antimony. (N.B. Measure the radioactivity of the irradiated arsenic calibration standards without further treatment).

\section{Results and discussion}

The time required for complete dissolution of a 1-g sample was ca. $30 \mathrm{~min}$ for $20 \mathrm{ml}$ of $5 \mathrm{M}$ sodium hydroxide, ca. $150 \mathrm{~min}$ for $30 \mathrm{~m} l$ of hydrochloric acid containing $0.1 \mathrm{mg}$ of nick- el ions, and ca. $90 \mathrm{~min}$ for $30 \mathrm{ml}$ of aqua regia. Even after the most vigorous decomposition with $5 M$ sodium hydroxide, a decrease of the solvent volume was $1 \mathrm{~m} l$ or less and the aluminum found in the first absorption vessel was less than $1 \mathrm{mg}$. Therefore, loss due to mechanical entrainment of tiny liquid particles containing the desired trace elements in the escaping vapor seems to be negligible.

Experimental results for loss of antimony and arșenic due to partial volatilization during dissolution are summarized in Tables 1 and 2 . All calibration curves were linear over the

Table 2 Experimental results for arsenic

\begin{tabular}{|c|c|c|c|c|c|c|c|c|}
\hline \multirow{2}{*}{$\begin{array}{l}\text { Exp. } \\
\text { No. }\end{array}$} & \multirow{2}{*}{$\begin{array}{l}\text { Sample } \\
\text { taken }(g)\end{array}$} & \multirow{2}{*}{ Solvent } & \multirow{2}{*}{ Vessel } & \multirow{2}{*}{$\begin{array}{l}\text { Chemical } \\
\text { yield }(\%)\end{array}$} & \multirow{2}{*}{$\begin{array}{l}\text { Radioactivity } \\
(\mathrm{cpm})\end{array}$} & \multicolumn{3}{|c|}{ As } \\
\hline & & & & & & \multicolumn{3}{|c|}{$\mu \mathrm{g} \mathrm{ppm} \mathrm{in} \mathrm{Al}$} \\
\hline \multirow{4}{*}{$1^{* 1}$} & \multirow[b]{2}{*}{$\int 0.91$} & \multirow{2}{*}{$\begin{array}{l}5 M \mathrm{NaOH}, \\
20 \mathrm{ml}\end{array}$} & Decomposition & $88 * 8$ & $1495 * 10$ & 0.12 & 0.13 & \multirow[b]{2}{*}{0.21} \\
\hline & & & Absorption*4 & $82 * 8$ & $876^{* 10}$ & 0.07 & 0.08 & \\
\hline & \multirow{2}{*}{1.01} & \multirow{2}{*}{$\begin{array}{l}9 M \mathrm{HCl}, 30 \mathrm{ml} \\
(+0.1 \mathrm{mg} \mathrm{Ni})\end{array}$} & Decomposition & $84 * 8$ & $2658 * 10$ & 0.23 & 0.23 & \multirow{2}{*}{0.26} \\
\hline & & & Absorption*4 & $84^{* 8}$ & $290 * 10$ & 0.03 & 0.03 & \\
\hline \multirow{6}{*}{$2^{* 1}$} & \multirow{3}{*}{$(0.78$} & \multirow{3}{*}{$\begin{array}{l}5 M \mathrm{NaOH} \\
20 \mathrm{ml}\end{array}$} & Decomposition & $98^{* 9}$ & $1244^{* 10}$ & 0.10 & 0.13 & \multirow{3}{*}{0.14} \\
\hline & & & 1 st absorption $* 5$ & $90^{* 9}$ & $79 * 10$ & & & \\
\hline & & & 2 nd absorption $* 5$ & $39 * 9$ & $82 * 10$ & 0.01 & 0.01 & \\
\hline & \multirow{3}{*}{10.66} & \multirow{3}{*}{$\begin{array}{l}\mathrm{HCl}, 30 \mathrm{ml} \\
(+0.1 \mathrm{mg} \mathrm{Ni})\end{array}$} & Decomposition & $54 * 9$ & $974 * 10$ & 0.08 & 0.12 & \multirow{3}{*}{0.16} \\
\hline & & & 1 st absorption $* 5$ & $26^{* 9}$ & $246 * 10$ & & & \\
\hline & & & 2 nd absorption $* 5$ & $40^{* 9}$ & $195 * 10$ & $\int 0.03$ & 0.04 & \\
\hline \multirow{9}{*}{3} & \multirow{3}{*}{$(0.95 * 2$} & \multirow{3}{*}{$\begin{array}{l}5 M \mathrm{NaOH} \\
20 \mathrm{ml}\end{array}$} & Decomposition & 87 & $176^{* 11}$ & 0.11 & 0.12 & \multirow{3}{*}{0.18} \\
\hline & & & 1 st absorption $* 6$ & 91 & $85 * 11$ & & & \\
\hline & & & 2 nd absorption $* 6$ & 94 & $21^{* 11}$ & $\int 0.06$ & 0.0 & \\
\hline & \multirow{3}{*}{$1.00 * 3$} & \multirow{3}{*}{$\begin{array}{l}\mathrm{HCl}, 30 \mathrm{ml} \\
(+0.1 \mathrm{mg} \mathrm{Ni})\end{array}$} & Decomposition & 88 & $525^{* 12}$ & 0.15 & 0.15 & \multirow{3}{*}{0.18} \\
\hline & & & 1 st absorption ${ }^{* 6}$ & 92 & $71^{* 12}$ & 0 & 003 & \\
\hline & & & 2 nd absorption $* 6$ & 92 & $31^{* 12}$ & & 0.03 & \\
\hline & \multirow{3}{*}{$1.01 * 3$} & \multirow{3}{*}{$\begin{array}{l}\text { Aqua regia } \\
\quad 30 \mathrm{ml}\end{array}$} & Decomposition & 90 & $623^{* 12}$ & 0.18 & 0.18 & \multirow{3}{*}{$\int 0.18$} \\
\hline & & & 1 st absorption*7 & 91 & $0 * 12$ & 0 & & \\
\hline & & & 2 nd absorption $* 7$ & (not & rmined) & & & \\
\hline
\end{tabular}

*1 Irradiation time: $20 \mathrm{~min}$. Cooling time: $3 \mathrm{hrs}$.

*2 Irradiation time. $20 \mathrm{~min}$. Cooling time: $70 \mathrm{hrs}$.

*3 Irradiation time: $20 \mathrm{~min}$. Cooling time: $46 \mathrm{hrs}$.

*4 $100-\mathrm{m} l$ beaker containing $30 \mathrm{~m} l$ of $9 \mathrm{M} \mathrm{HCl}$.

*5 $100-\mathrm{m} l$ Erlenmeyer flask containing $30 \mathrm{~m} l$ of $\mathrm{HCl}$.

*6 Absorption tube containing $30 \mathrm{ml}$ of $\mathrm{HCl}$ and $5 \mathrm{ml}$ of $\mathrm{As}(\mathrm{II})$ carrier solution.

*7 Absorption tube containing $30 \mathrm{ml}$ of $\mathrm{HCl}$ and $5 \mathrm{ml}$ of $\mathrm{As}(\nabla)$ carrier solution.

*8 Nitrogen was passed into $9 \mathrm{M} \mathrm{HCl}$ solutions to expel $\mathrm{SO}_{2}$.

*9 Nitrogen was passed into hot $9 \mathrm{M} \mathrm{HCl}$ solutions to expel $\mathrm{SO}_{2}$.

*10 Measured 25 hrs after the end of irradiation, and corrected for chemical yield.

*11 Measured $79 \mathrm{hrs}$ after the end of irradiation, and corrected for chemical yield.

*12 Measured $55 \mathrm{hrs}$ after the end of irradiation, and corrected for chemical yield, 
range of $0 \sim 1 \mu \mathrm{g}$ of antimony or arsenic. Because of relatively low temperatures during the dissolution, the chief volatile species are likely to be hydrides, i.e., stibine and arsine. While there is some possibility of incomplete absorption of the volatile species, the following may be concluded from the above results.
For aluminum metal samples containing fractional ppm of antimony and arsenic, aqua regia is most recommended as a solvent. On the contrary, $5 M$ sodium hydroxide, which is often prefered because of rapid dissolution, should not be used. Hydrochloric acid can be used only for antimony. 